\title{
Measures of Satisfaction from the Implementation of Quality Standards in Higher Education Institutions of Saudi Arabia
}

\author{
Dr. Fahd Mohammad Alonazy \\ Assistant Professor \\ College of Public Health and Health Informatics, Al-Bukayriyah \\ Qassim University, Kingdom of Saudi Arabia \\ Dr. Ghulam Muhammad Kundi \\ Professor of Management Sciences \\ Department of Public Administration, Gomal University, DIKhan, Pakistan
}

\begin{abstract}
Background: The purpose of this papers was investigate into the satisfaction from implementation of quality standards in higher education institutions of Saudi Arabia. Quality is the key factor in achieving accreditation. Researchers believe that implementation of quality standards is closely related with the satisfaction of the students and thus quality standards in higher education institutions indirectly plays a pivotal role to improve the outcomes of the universities.
\end{abstract}

Method: Hermeneutics, discourse and heuristic were employed for data analysis with the help computer based qualitative package ATLAS.ti.

Findings: The findings shows that there was a satisfaction about the implementing of quality standards in higher education of Saudi Arabia in the large universities, however, on the other hand, the also identified that findings the main reasons of dissatisfaction with implementation of quality standards in some small universities.

Conclusion: The study concludes that implementation of quality standards is yet to be dome due to slow pace and they are just in papers and yet until now they have not been put into effect in reality.

Keywords: Quality Standards, Quality Assurance, Quality Implementation, Students Satisfaction, Higher Education Institutions (HEIs), Saudi Arabia.

DOI: $10.7176 / \mathrm{DCS} / 9-9-03$

Publication date:September $30^{\text {th }} 2019$

\section{Introduction}

Quality is the name of excellence that differentiate the product or service rendered by different competing organizations and it is closely linked with the overall satisfaction of the clients/ users ( $\mathrm{Zu}, 2009)$. According to American marketing Association consumer or client is a king, and therefore, organization focus and divert all their activities towards satisfaction of their customers in order to lock in maximum customers and lock out the maximum competitors, quality is the competitive weapon which do serve the same if quality standards /protocols are properly developed and implemented (Baxter \& Hirschhauser, 2004).

The word quality is believed to have been derived from Latin quālitās "of what sort" so it is "the standard of something as measured against other things of a similar kind; the degree of excellence of something", and quality is categorized into good quality, poor quality, no quality, whereas, the individual judgment of quality depends on various aspects, e.g. experience, education, environment (Benner \& Veloso, 2008). If an organization do fulfil its promise and commit as envisioned in its quality statement and policy, it is thus named as quality.

The Islamic teaching also emphasize on the assurance of quality. Do good deeds and show noble virtues, as Allah is watching you 24/7, fulfil your promise: "and fulfill the promise, surely (every) promise shall be questioned about." (Surah al-'Isrā', 17:34) and, "O you who believe! Why do you say that which you do not do? It is most hateful to Allah that you should say that which you do not do." (Surah as-Saff 61:2-3).

The well-known business tycoon of the west and pioneer of the Ford Motors, according to Henry Ford "quality means doing it right when no one is looking". So the evidence of good quality is that when the customer returns and not the product (Grigoroudis \& Siskos, 2009).

Though, it is very difficult to define quality in higher education as it complex and complicated and a relative phenomenon, hence it engrosses numerous difficult- bonds due to its complex oddity (Koilias, Kostoglou, Garmpis, \& Van der Heijden, 2011). Harvey and Green (1993) however, have suggested to use a structural development of quality, which consists of five dimensions, 1 the Quality as exceptional, 2. Quality as perfection or consistency, 3. Quality as fitness for purpose, 4. Quality as value for money, and 5. Quality as transformation. Furthermore, researchers like, Harvey \& Williams (2010) added one more attribute named as Quality as transformation. Similarly, an eminent quality researcher, Corredor and Goni (2010) described quality as "a highly contested concept that has multiple meanings, which are linked to higher education" that how it is perceived. Besides, Shrikanthan and Dalrymple (2003) identified a significant relationship between the implementation of quality 
standards and satisfaction by the supervisor in higher education institutions, while Harvey and Green's presented the following dimensions of quality: 1. Providers i.e. the funding agencies and community where quality is interpreted as value for money, 2. The users of products i.e. the existing and future students, here quality is interpreted in terms of excellence, 3 . The users of outputs i.e. employers and this regard the quality is taken as fitness for purpose, and last but not least 4 . The employees working in that area/ sector i.e. the academics and administrators, here quality is construed as consistency. According to Van Kemenade et al. (2008) quality is to be described with four parts: 1. the object, 2. standard, 3. subject and, 4. the value, these expounds on four value systems on the quality and the quality management, which includes the control, the continuous improvement, the commitment and the breakthrough.

Quality management systems have been established to direct and control an organization with regard to quality (ISO 9000):2000 (Magd, H., \& Curry, A. (2003). The quaity management systems consists of the quality planning (crireia driven), it defines the standards and determines how to satisfy those standards (Koilias et al., 2011). It also lays out the roles and responsibilities, resources, procedures, and processes to be utilized for quality control; quality assurance (prevention driven), it is the review to ensure aligning with the quality standards, an assessment is provided here, it is planned and systematic quality activities, which provide the confidence that the standards will be met; quality control (inspection driven), it addresses the assessment conducted during quality assurance for corrective actions and measure specific results to determine that they match the standards. According to Shure, Jansen., \& Harskamp (2007), it uses statistical process control (SPC), which provides a methodology for monitoring the process and to identify special causes of variation and signal the need to take corrective action when appropriate and it it relies on control charts (Feng, Prajogo, Tan, \& Sohal, 2006). However, the most prominent is the concept of organization wide management philosophy i.e. continuously improving the quality of products / services and its processes. Whilst continuously quality improvement is the responsibility of everyone who is involved in the production or use of the products or services offered and hence is interested in its quality.

Higher education of any country plays significant role in transformation of the society from fused to prismatic and then to the diffracted as grouped by Riggs (Heady, 2013) for comparative analysis. It is the education sector upon which uplift of a nation's depend for economic growth and development. Higher education produces graduates according to the precise need of the country in order to cater the local, nation and sometimes international requirements with regards to different sectors of the economy and considered as the back bone of any economy. The quality of the produced graduates make a difference. The Saudi higher education systems is gradually moving ahead towards excellence and therefore, the government is more focusing on the quality of education and not just merely on the education. The Saudi National Commission for Academic Accreditation \& Assessment (NCAAA) is the official agency established in 2004 with the vision to develop and ensure implementation of the quality standards in Saudi higher education institutions (NCAAA, 2013). This official accreditation and quality standards of Saudi Arabia body is working under the board of directors, the members include both from public and private sector experts i.e. director are drawn from government, institutions and industry professionals. This study was undertaken to measure the satisfaction of the quality supervisors about the implementing of quality standards in higher education in Saudi Arabia. This paper relates to the accreditation and quality assurance theme.

\section{Logical Argumentation from the Review of the Literature}

Several research studies have been under taken to investigate the relationship between satisfactions from the quality standard implementation in higher education institutions around the globe in relation to the HEIs performance, likewise, they found variation and sometime contradictory results. Researchers like, Bou- Llusar et al. (2009), Tari, Molina and Castejon (2007) and Kaynak (2003) have found positive and significant relationship between these two significant factors however, researchers like Corredor and Goni (2010); Macinati (2008) and Benner and Veloso (2008) found results contrary to above mentioned studies, their studies identified negative relationship between satisfaction and implementation of the quality standards with regards to management practices especially in the universities.

More recently, several researches in the field of quality in higher education have also been carried out, which highlight the significant of the related notion. If we explore the history of quality in higher education, we can trace back the history of application of quality assurance in higher education from the quality assurance schemes in European Higher Education, which were for the first time introduced respectively in France (1984), the UK (1985) and the Netherlands (1985) as reported by Westerbeijden et al. (2007).

The significance of the quality assurance in HEIs was acknowledged by the Louvain meeting (April 2009) in which minister from European union members countries participated, they stressed to enhance quality in European Higher Education institutions thus universities throughout the Europe adopted external evaluation systems and also introduced an ISO9001: 2000 certification being integral part of their internal quality management system (Terziovski, \& Power, 2007; Hutyra, 2005; Lagrosen, Seyyed-Hashemi, \& Leitner, 2004).

It is believed by the researchers like, Feng, Prajogo, Tan, \& Sohal, (2006) and Shemwell et al. (1998) that quality of the services is diligently connected with the customer's satisfaction. They further asserted that the 
perceived quality of HEIs depends on satisfaction of the students. Studies conducted by Martensen et al. (2000) in Europe has used the European Customer Satisfaction Index in order to measure the student's perceived quality and satisfaction from their HEIs. Similarly, Sureshchandar et al. (2002) also explored the relation between service quality and customer satisfaction with regards to perceived service quality whereas, Elliot and Shin (2002) worked on the positive effect of the quality with regards to the student's satisfaction and concluded that their satisfaction plays significant role in motivation, retention of the students besides recruiting efforts. Bigne et al. (2003) found similar results and found that the overall service quality is significantly associated with students satisfaction, the findings of the Bigne etal. Were further confirmed by Ham and Hayduk (2003) who reports that there is a positive association between perception of service quality and satisfaction of the students? Likewise, Suhre et al. (2007) also investigated the impact of quality on satisfaction of the students and their academic accomplishment and dropout. They find that student accomplishment largely depends on the program satisfaction inter alia the metamorphoses in academic ability.

More recently, Lee and Tai (2008) explored some of the critical factors with regards to satisfaction from quality standards and quality assurance practices in HEIs, which might have significant impacts on the student's satisfaction in higher education institutions. Kim and Richarme (2009) while exploring the phenomena of satisfaction from quality standards implementation in HEIs have find students satisfaction is one of the best indictors which pave way for improvement and result into the positive financial implications for institutions. Researcher who are sing the Kano model have observed that there is an asymmetric relationship between quality and satisfaction (Tsirintani et al., 2010).

Martensen et al. (2000) suggested the use of multi-criteria methodology to understand the dynamism of the issue of satisfaction from the quality standards implementation. He suggest to connect the features of the quality of education services rendered by HEIs to the student satisfaction, his model focuses on the several satisfaction criteria and sub-criteria with varying quality attributes of the services offered by them i.e. the study program, teaching environment, the staff, and the tools and equipment etc. used during teaching and learning process. Furthermore, a study conducted by Westerheijden Hulpiau, \& Waeytens (2007) have recommended, to link the proposed multi-criteria with student satisfaction and contends that actions is need to be undertaken to improve the overall performance of these factors.

\section{Perspective on Quality Standards in Saudi Arabian HEIs}

The Saudi agency NCAAA for quality implementation in HEIs was established in 2004 as an independent authority for accreditation and quality assurance by Higher Council of Education of the Kingdom of Saudi Arabia. The NCAAA is responsible to set out by-laws in the field of Higher Education; yet, in general its description of responsibilities include its role in the system of accreditation and quality assurance, whereas its key role is to establish standards, criteria and procedures for academic assessment and accreditation besides provision of training and support to the faculty and staff responsible for establishment and development of quality assurance systems in HEIs; furthermore, NCAAA also evaluate and assist the HEIs in development of quality assurance documents and reports that are needed for their accreditation process; the NCAAA is also responsible to manage and coordinate the external accreditation reviews of the specific programs as well as that of the institutions. The quality establishment and development process id done in three stages, 1: The System for Quality Assurance and Accreditation, 2: Internal Quality Assurance Arrangements, and 3: The External Reviews for Accreditation and Quality Assurance (NCAAA, 2013).

Al Arefa \&Waqran (2007) identified lack of activate usage and implementation of the modern information systems in all administrative processes as cause of poor implementation of the quality standards in Saudi universities, he further pointed out that there is no additional incentives program for the people involved in the quality department of Saudi universities in order to encourage their productivity and further to improve the efficiency by adequately and timely implementing the standards, furthermore there is lack of awareness and in capacity and incapability on part of the administration with regard to quality concepts. Likewise, there is lack of proper training facilities and refresher courses and workshops to raise the level of awareness about significance of quality and to enhance the knowledge and skills of the quality related professionals.

Al Harbi (2002), while investigating the reason of dissatisfaction of the students from the quality standards and quality assurance practices have observed that there is no or very weak culture among teaching staff which needs their orientation through arrangement of workshops, seminar in order to cultivate new culture of quality in the universities. He also posited out lack of incentive program as major barriers towards increasing the teaching capabilities and promoting the academic research.

Further, he contends that there is need to improve the skills and knowledge of information technology in education besides continuous development and review of the curriculum and course contents. Agreeing to the AlHarbi (2002), Al Arefa \&Waqran (2007) further reports satisfaction of quality is also related with the physical and infrastructural facilities with regards to classroom facilities in terms of illumination, ventilation and availability of technology. 
With this context, the review of the literature highlights that most of research studies have been conducted in western context that explored the relationship between these two factors yet, there is a dearth and merely very few studies can be found in in the gulf perspective.

Despite the dearth of literature, however, some of the studies in Saudi perspective have identified that following weak areas responsible for weak or otherwise slow implementation of the quality standards in HEIs of Saudi Arabia, these include, customer/ students have no role in measuring the HEIs performance, and thus they have no effect on the organizational performance, however the top management is committed which is a positive sign of transformation and modernization of these institutions (QAAAU, 2009).

Thus the major determinants along with the criteria and sub criterial emerged from the literature review after operationalization that measure the students satisfaction from the implementation of quality standards in HEIs of Saudi Arabia are presented in the below table-1 that describes the critical factors of the issue under study.

Table-1 Determinants of student's satisfaction along with criteria and sub criteria

\begin{tabular}{|c|c|}
\hline $\begin{array}{c}\text { Criteria for assessment of student's satisfaction from } \\
\text { Implementation of Quality Standards in HEIs. } \\
\text { Criteria }\end{array}$ & Sub-criteria \\
\hline 1. Program of the Study & $\begin{array}{l}\text { a. Adequacy of the program, } \\
\text { b. Organization of the program, } \\
\text { c. Workload of the program, } \\
\text { d. Profession -Contiguity, } \\
\text { e. Course Revision and update, } \\
\text { f. Modules variability }\end{array}$ \\
\hline 2. Teaching Staff & $\begin{array}{l}\text { a. Kindly behavior, } \\
\text { b. Preparation adequacy, } \\
\text { c. Communication Skills } \\
\text { d. Teaching methodology, } \\
\text { e. Objectivity in delivery } \\
\text { f. Availability of teachers in office }\end{array}$ \\
\hline 3. Physical Infrastructure/ Equipments & $\begin{array}{l}\text { a. Building adequacy/ suitability, } \\
\text { b. Other facilities, } \\
\text { c. Education material } \\
\text { d. Laboratories adequacy, } \\
\text { e. Laboratories timing, } \\
\text { f. Library timing } \\
\text { g. Library / reading room, } \\
\text { h. Borrowing Procedure, } \\
\text { i. Digital Library System } \\
\end{array}$ \\
\hline 4. Administration and its Services & $\begin{array}{ll}\text { a. } & \text { Correspondence } \\
\text { (conventional/online), } \\
\text { b. Kindly Behavior, } \\
\text { c. Clear informing } \\
\text { d. Service Speed/ Reliability }\end{array}$ \\
\hline 5. Credibility/ Fame & $\begin{array}{l}\text { a. Expectations of Students, } \\
\text { b. Recognition by Students, } \\
\text { c. Representation-Promotion }\end{array}$ \\
\hline
\end{tabular}

Source: Developed from the Review of the Literature of the Current Study

\section{Methods and Tools}

In order to understand the issue under investigation, Review of the existing literature was done. Likewise, according to the qualitative research approaches of data analyses, the researchers have examined, categorized, tabulated and recombined the data with the help of hermeneutics (James, 1992), discourse (Max, 1990) and heuristic (Moustakas, 1990) analyses.

In a later step, the computer based software ATLAS.ti was employed for qualitative data analysis by feeding the major concepts and variables of the study into ATLAS.ti. Coding, extraction of quotes and memos creation was done with the help of ATLAS.ti.

The schematic diagram of theoretical framework given below explain the association between DV and IVs in the background of satisfaction about implementation of quality standards in higher education of Saudi Arabia. 


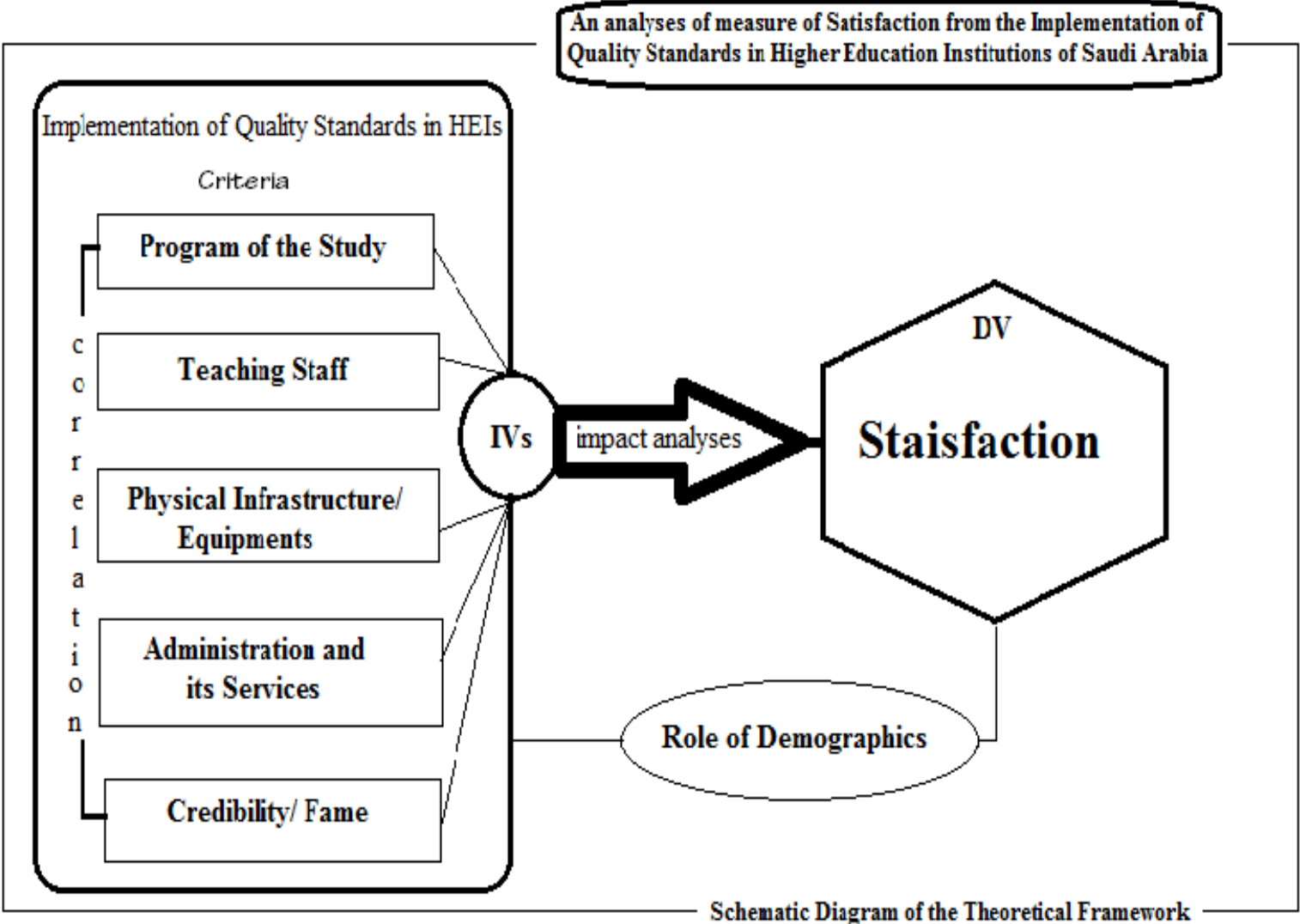

Figure-1 Schematic Diagram of the Theoretical Framework

\section{Conclusions, Suggestions \& Implications}

According to a famous saying "there is always room for improvement" because the human created organizations and systems cannot me marked as perfect, as the perfection only lies with Allah Almighty. Err is to human, so mistakes, errors, omissions and deficiencies are always expected to be the part and parcel of the human created organizations and systems. This demand strict watch over, monitoring, evaluation and direction and control in the form of revisiting the objectives, policies, plans, programs and decisions in order to keep pace in tune with the modern day changers and challenges. Therefore, it is not only essential rather imperative to keep on improving the quality of service as one of the most important responsibility and task of the higher education institutions.

Researchers, however, have developed several arguments and these argument which are based on logic also support their argument that there is close relationship between the service quality and students/clients satisfaction. Likewise, few of the studies, discussed above, however, contend that the perceived quality of HEIs largely depends on the satisfaction and therefore, subsequently it is the increasing customer's/ students satisfaction that leads these HEIs to an upswing in service quality.

The current study in hand, yet employed the methodology of multi-criteria while analyzing the level of students satisfaction from the implementation of quality standards in HEIs of Saudi Arabia in order to shed more light in understanding the association of student satisfaction with characteristics of the quality through a set of criteria and sub-criteria which represent different dimensions of the quality standards and their implementation process in the Saudi HEIs.

Based on our qualitative analyses of the related literature, this study has found that there is a slight or marginal need for improvements as implementation of quality stands in larger universities is smooth as planned, yet, the results points to confirm the importance of the investigation and analyses of the satisfaction of the students and their implications that are given to definite quality dimensions of higher education. The study found interesting results that are consistent with the previous studies for example, students take more interest in the criteria of satisfaction that consider the demanding level of the students as displayed in the criteria. More precisely, researcher believes that students give high importance to the credibility and fame of the programs of the study in these high seat of learnings, because the credibility reflect their complete quality and reliability. Similarly, it is argued that most of the studies contends that the criteria like, program of the study, the role of the teaching staff, the services offered the administrative and the equipment and tools are less important.

The study concludes that a one of the most significant indicator of the satisfaction from the quality standard 
implementation for Saudi HEIs could be the adaption of a satisfaction barometer, while evaluating the level of satisfaction from the quality standards in these higher education institutions. This necessitates the development of such and system and mechanism that should regularly and frequently monitor the satisfaction of the students and that should be linked quality policies and actions. The later one may be also associated with the external evaluation system of the quality standards, thus combination of the internal and external assessments and evaluation will result into a cohesive and a structured quality framework through which the pace of the implementation of the quality standards can be accelerated thereby the satisfaction of the students could be achieved which imperative to earn credibility and good name in the education sector.

With this background, the study suggest that the higher education institutions in Saudi Arabian context, must follow quality assurance $\&$ accreditation as a vehicle to materialize their goals and in smooth implementation of the quality standards, for this purpose, it is further suggested to disseminate the awareness culture of quality among their personnel through on the job training programs by employing range of means in order to assure the quality of their educational services they render meet the national demands in general and the expectations of the students in particular.

Furthermore, this study suggest that a built in mechanism must be put into quality systems so that through continuous improvement these institutions could achieve the high level of independence, credibility and stability and for this purpose they need to develop an overall strategic plan with clear vision for quality assurance. And the best option to know the quality of educational services they offer is to get an accreditation from the national or international institutions/ agencies this could pave a way the recognition of these HEIs locally, nationally, as well as internationally.

\section{References}

Al Arefa, A. \&Waqran, A. (2007).Obstacles to apply the quality of public education from the viewpoint of the officials, educational supervisors and in Al-Bahah educational region. Study presented at the Fourteenth Conference (Quality in Education), Al-Qassim, Saudi Arabia

Al Harbi, H. M. (2002). Trends in the Saudi Arabian academic body towards applying the principles of total quality management. Journal of Educational Sciences, 5(1), 203-231.

Baxter, L. F., \& Hirschhauser, C. (2004). Reification and representation in the implementation of quality improvement programs. International Journal of Operations \& Production Management, 24(2), 207-224.

Benner, M. J., \& Veloso, F. M. (2008). ISO 9000 practices and financial performance: a technology coherence perspective. Journal of Operations Management, 26, 611-629

Bigne, E., Moliner, M., \& Sanchez. J. (2003). Perceived quality and satisfaction in multiservice organizations. The case of Spanish public services. The Journal of Services Marketing, 17, 420-442. doi:10.1108/08876040310482801

Bou, J. C., B, E. T., Vicete, R. P. \& Martin, I. B. (2009). An empirical assessment of the EFQM excellence model: Evaluation as a TQM framework relative to the MBNQA Model. Journal of Operations Management, 27, 122.

Corredor, P., \& Goni, S. (2010). TQM and performance: Is the relationship so obvious? Journal of Business Research, 22(5), 529-538.

Elliott, K. M., \& Shin, D. (2002). Student satisfaction: An alternative approach to assessing this important concept. Journal of Higher Education Policy and Management, 24, 198-209. doi:10.1080/1360080022000013518

Feng, J., Prajogo, D. I., Tan, K. C. \& Sohal, A. S. (2006). The impact of TQM practices on performance: A comparative study between Australian and Singaporean Organizations. European Journal of Innovation Management, 9(3), 269-278.

Grigoroudis, E., \& Siskos, Y. (2009). Customer Satisfaction Evaluation. Oklahoma: Springer.

Ham, L., \& Hayduk, S. (2003). Gaining competitive advantage in higher education: Analyzing the gap between expectations and per-ceptions of service quality. International Journal of Value-Based Ma- nagement, 16, 223-242. doi:10.1023/A:1025882025665

Harvey, L., \& Green, D. (1993). Defining quality. Assessment and Evaluation in Higher Education, 18,9 , 34. doi:10.1080/0260293930180102

Harvey, L., \& Williams, J. (2010). Fifteen years of quality in higher education. Quality in Higher Education, 16, 3-36.

Heady, F. (2013). Public Administration: A Comparative Perspective. McGraw-Hill INC., New York, USA.

Hutyra, M. (2005). Quality management system as the part of univer-sity management, paper presented at Integrating for Excellence, Sheffield, 15-17 June.

James P. Gee. (1992). Discourse analysis. In: LeCompte, M. et al. (2001). The handbook of qualitative research in education ((Eds). chapter 6). 1992. San Diego, Academic Press, USA.

Kaynak (2003). The relationship between total quality management practices 7 their effects on firm performance. Journal of Operations Management, 21(4), 405-435. 
Kim, J. W., \& Richarme, M. (2009). Applying the service-profit chain to internet service businesses. Journal of Service Science and Man-agement, 2, 96-106. doi:10.4236/jssm.2009.22013

Koilias, C., Kostoglou, V., Garmpis, A., \& Van der Heijden, B. (2011). The incorporation of graduates from Higher Technological Education into the labour market. Journal of Service Science and Management, 4, 8696. doi:10.4236/jssm.2011.41012

Lagrosen, S., Seyyed-Hashemi, R., \& Leitner, M. (2004). Examination of the dimensions of quality in higher education. Quality Assurance in Education, 12, 61-69. doi:10.1108/09684880410536431

Lee, J. W., \& Tai, S. W. (2008). Critical factors affecting customer satisfaction and higher education in Kazakhstan. International Jour-nal of Management in Education, 2, 46-59.

Macinati, M. S. (2008). The relationship between quality management systems and organisational performance in the Italian National Health Services. Health Policy, 85:228-241.

Magd, H., \& Curry, A. (2003). ISO 9000 and TQM: are they complementary or contradictory to each other? The TQM Magazine, 15(4), 244-256.

Manaul of Quality Assurance and Accreditation of Arab Universities 'QAAAU' (2009). The Association of Arab Universities, (Secretariat), the Board of Quality Assurance and Accreditation, Jordan: Amman.2009.

NCAAA (2013).Manual: Orientation of Quality Assurance and Accreditation Saudi Arabia 'NCAAA'. Part I, Saudi Arabia, Riyadh

Martensen, A., Grǿnholdt, L., Eskildsen, J. K., \& Kristensen, K. (2000). Measuring student oriented quality in higher education: Application of the ECSI methodology. Sinergie-Rapporti di ricerca, 18, 371-383.

Max V Manen. Hermeneutical Analysis: Researching lived experience. State University of New York Press. 1990. USA.

Moustakas C. Heuristic research. Academic Press, Newbury Park. 1990. USA.

Schertzer, C. B., \& Schertzer, S. M. B. (2004). Student satisfaction and retention: A conceptual model. Journal of Marketing in Higher Edu- cation, 14, 79-91. doi:10.1300/J050v14n01_05

Shemwell, D. J., Yavas, U., \& Bilgin, Z. (1998). Customer-service provider relationships: An empirical test of a model of service qual-ity, satisfaction and relationship oriented outcome. International Journal of Service Industry Management, 9, 155-168. doi:10.1108/09564239810210505

Shrikanthan, G., \& Dalrymple, J. F. (2003). Developing a holistic model for quality in higher education. Quality in Higher Education, 8, 215-224. doi:10.1080/1353832022000031656

Shure, C. J. M., Jansen, E. P. W., \& Harskamp, E. G. (2007). Impact of degree program satisfaction on the persistence of college students. Higher Education, 54, 207-226. doi:10.1007/s10734-005-2376-5

Surah al-'Isrā', 17:34 (2016). Quran: The English Commentary, Ummul Qurra, The Makkah, Saudi Arabia.

Surah as-Saff 61:2-3 (2016). Quran: The English Commentary, Ummul Qurra, The Makkah, Saudi Arabia.

Sureshchandar, G. S., Rajendran, C., \& Anantharaman, R. N. (2002). The relationship between service quality and customer satisfaction- A factor specific approach. Journal of Services Marketing, 16, 363- 379. doi: $10.1108 / 08876040210433248$

Tari, J. J., \& Molina, J. F. (2010). Integration of quality management and environmental management systems: Similarities and the role of the EFQM model. The TQM Journal, 22(6), 687-701.

Tari, J. J., Molina, J. F., \& Castejon, J. L. (2007). The relationship between quality management practices and their effects on quality outcomes. European Journal of Operations Research, 183, 483-501.

Terziovski, M., \& Power, D. (2007). Increasing ISO 9000 certification benefits: a continuous improvement approach. International Journal of Quality \& Reliability Management, 24(2), 141-163.

Tsirintani, M., Giovanis, A., Binioris, S., \& Goula, A. (2010). A new modeling approach for the relationship between quality of health care services and patient's satisfaction. Journal Nosileftiki, 49, 40-52.

Van Kemenade, E., Pupius, M., \& Hardjono, J. W. (2008). More value to defining quality. Quality in Higher Education, 14, 175-185. doi:10.1080/13538320802278461

Westerheijden, D. F., Hulpiau, V., \& Waeytens, K. (2007). From de-sign and implementation to impact of quality assurance: An overview of some studies into what impacts improvement. Tertiary Education and Management, 13, 295-312. doi:10.1080/13583880701535430

$\mathrm{Zu}, \mathrm{X}$. (2009). Infrastructure and core quality management practices: how do they affect quality? International Journal of Quality \& Reliability Management, 26(2), 129-149. 